\title{
ENSAYOS
}




\section{Posicionamiento freireano ante la formación del profesorado: el compromiso político de educador}

Virginia Guichot Reina ${ }^{1}$

\section{Resumen}

Paulo Freire (1921-1997) puede ser considerado como uno de los pedagogos más influyentes del siglo XX. Sus numerosos libros y artículos aparecen citados continuamente en cualquier ensayo educativo que se ocupe de cómo intervenir pedagógicamente desde la base de una ética humanista, emancipadora, que toma el diálogo, la comunicación con los otros, como rasgo distintivo. En este artículo, se pretende exponer las líneas esenciales de la pedagogía de la posibilidad freireana, nivel superior de la pedagogía crítica, que impele al educador a un compromiso político, un docente que habrá de poseer unas cualidades que le capaciten para el logro de los ciudadanos democráticos por los que apuesta la ética humanista del brasileño. Para ello, se sigue un esquema donde se parte del marco teórico-filosófico que anima su propuesta educativa: su antropología, teoría del conocimiento y ética. Posteriormente, se aterriza en su concepto de educación, de enseñanza-aprendizaje, y éste nos conduce a la figura de ese educador comprometido socialmente, que entiende que todo acto educativo es un acto político y que apuesta, con su praxis, por un mundo mejor.

Palabras clave: filosofía de la educación, pensamiento educativo contemporáneo, pedagogía crítica, compromiso político del educador, pedagogía de Paulo Freire, pedagogía de la posibilidad

\section{Summary}

Paulo Freire (1921-1997) can be considered as one of the most influential educators of the 20 th century. Many are the educational, pedagogical essays that consider his humanist, emancipating and intercommunicative viewpoint of pedagogy the most remarkable feature of his works. As a matter of fact, this paper tries to display the essential lines of his socalled pedagogy of the possibility. This one is a further step in critical pedagogy, the aim of which is both the political commitment of the educator as much as the teacher's qualification that, according to the Brazilian's humanist ethics, may quarante democratic citizenz as a result. The scheme to follow is, first, the theoretical and philosophical frame of his educational proposal: his anthropology, theory of knowledge and ethics. Later one deals with the concept of education and the learningteaching concept, what takes us to the figure of the so-called educator with a deep social commitment, the one for whom any educative act is a political act and who, with his praxis, bets on a better world.

Key words: philosophy of education, contemporary educational thought, critical pedagogy, political commitment of the educator, Paulo Freire's pedagogy, pedagogy of the possibility

Paulo Freire (1921-1997) puede ser considerado como uno de los pedagogos más influyentes del siglo XX, "admirado y seguido por las personas progresistas, y respetado incluso por quienes mantienen concepciones ideológicas más conservadoras", tal como indica Jurjo Torres en el prólogo de la última obra del brasileño, Pedagogía de la

\footnotetext{
* Artículo recibido el 3 de diciembre de 2003 y arbitrado el 16 de abril de 2004.

1 Profesora titular Universidad de Sevilla (España). Miembro del grupo de investigación Historia de las Enseñanzas no Obligatorias en el Distrito Universitario de Sevilla (1845-1990). E-mail: vguichot@yahoo.e 
Indignación (2001: 12), una de esas personas cuyos planteamientos educativos no nos dejan indiferentes, sino que nos impelen a posicionarnos, sea a favor, sea en contra. Sus numerosos libros y artículos aparecen citados continuamente en cualquier ensayo educativo que se ocupe de cómo intervenir pedagógicamente desde la base de una ética humanista, emancipadora, que toma el diálogo, la comunicación con los otros, como rasgo distintivo. La propuesta de Paulo Freire va unida a un término que posee irresistible atractivo para cualquier educador, pedagogía de la posibilidad, o pedagogía de la esperanza, como él gustaba de llamarla. Una pedagogía que bebe de la sociología crítica de la educación, que a principios de los setenta subrayó la idea de la escuela como agente de reproducción social, económica y cultural al servicio de la clase dirigente, pero que posee la fuerza suficiente para sobrepasarla y abrir alternativas dentro del panorama educativo en la lucha por un mundo más justo, más libre. Es el gran mensaje de la utopía, la dialéctica entre la denuncia y el anuncio, palabra clave en el pensamiento de Freire.

La denuncia freireana se dirige a una sociedad deshumanizada, en la que la democracia es puramente formal, en la que se fortifica el papel de los poderosos; fundada en la ética del mercado que, dejándose llevar sólo por el lucro, imposibilita la misma democracia; que acepta la perversa ideología de la muerte de las ideologías y de las clases sociales; que asume el fatalismo para los países más débiles de la globalización económica (Torres, 5859). Y ante ese espectáculo indignante, el anuncio, la reivindicación de un proyecto por el que hay que luchar, en el que el poder político garantice las libertades, los derechos y los deberes, la justicia ${ }^{2}$. Freire confía en la capacidad transformadora del ser humano, en su competencia práxica ${ }^{3}$, defendiendo de esta forma una concepción de la historia como posibilidad que concede al sujeto la facultad de decidir el mañana.

Unida a esta capacidad de elección entre diversas alternativas que caracteriza a los hombres y mujeres, a ese poder para construir la historia, el pedagogo brasileño señala el compromiso ético-político por un mundo más justo que hemos de abrazar todos los seres humano $^{4}$. Y habla de la necesidad de este fuerte compromiso por parte del educador, dándose cuenta de la enorme responsabilidad de su tarea. Nunca pensó que la educación fuera el único motor para cambiar la sociedad, pero siempre creyó que sin ella, la utopía democrática nunca se realizaría. Freire se rebela ante la terrible falacia de la neutralidad de la educación, ante la falta de conciencia de que todo acto educativo es un acto político, cargado de ideología, de valores. Conmina a los educadores a que se pregunten qué proyecto social se esconde debajo de sus prácticas educativas cotidianas porque lo que

\footnotetext{
${ }^{2}$ En los últimos años de su vida, Paulo Freire es consciente de la amenaza que supone el avance de las políticas económicas neoliberales en las dictaduras latinoamericanas y en las democracias formales; de cómo tratan de generar una gran impotencia en la gente en cuanto a sus posibilidades de imaginar y luchar por otras alternativas. Las nuevas sociedades de consumo, promovidas desde las opciones neoliberales, sin recurrir a medidas de fuerza o de coacción, sino, en gran medida, sobre la base de distorsionar las finalidades de la educación de la ciudadanía y apoyándose en un férreo control de los medios de comunicación de masas, están llevando a ciudadanos y ciudadanas a hacer dejación de sus derechos cívicos. Como resultado de ello, una gran parte de las personas quedan únicamente reducidas a consumidoras -quienes poseen recursos económicos para ello-, mientras otro importante colectivo de seres humanos se ve excluido de la sociedad, en la medida en que no dispone de unos mínimos recursos económicos para participar en el banquete consumista (J. Torres Santomé, en Prólogo de Pedagogía de la indignación, 2001: 15-16).

${ }^{3}$ De hecho, en el prólogo a la Pedagogía del oprimido, el pedagogo brasileño escribe: "A través de estas páginas quisiera dejar claro lo siguiente: mi creencia en las personas, mi fe en los hombres y en las mujeres y en la creación de un mundo en que sea más fácil amar".

4 "La pedagogía de Paulo Freire es una llamada a la necesidad de la utopía, a la tarea de construir 'propuestas de posibilidad', a no conformarse pensando que la realidad fue y es siempre así; algo que propugnan los discursos más conservadores o los del pensamiento único" (J. Torres, en Prólogo de la edición española de Pedagogía de la indignación, 2001: 13).
} 
es claro es que siempre existe uno: para qué educan, a favor de qué, en contra de quién, en defensa de qué intereses, en oposición a qué ideologías.

En este artículo, se pretende exponer las líneas esenciales de esa pedagogía de la posibilidad freireana, ese nivel superior de la pedagogía crítica, que impele al educador a un compromiso político, un docente que habrá de poseer unas cualidades que le capaciten para el logro de los ciudadanos democráticos por los que apuesta la ética humanista del brasileño. Para ello, se sigue un esquema donde se parte del marco teórico-filosófico que anima su propuesta educativa: su antropología, teoría del conocimiento y ética. Posteriormente, se aterriza en su concepto de educación, de enseñanza-aprendizaje, y éste nos conduce a la figura de ese educador comprometido socialmente, que entiende que todo acto educativo es un acto político y que apuesta, con su praxis, por un mundo mejor.

\section{Marco filosófico de la pedagogía freireana: antropología, epistemología y ética}

Toda teoría de la educación parte de una antropología, de una teoría del conocimiento, de una ética que le da sentido. Entender a Freire supone comprender la filosofía que da significado a sus propuestas educativas. En la base de las mismas, se halla la idea de apertura, de inacabamiento del ser humano. Éste no es un ser concluido, terminado; tiene que ir construyendo su existencia. A diferencia del resto de los animales, posee conciencia de su incompletitud, es capaz de reflexionar acerca de sí mismo y de saberse viviendo en el mundo. Es el homo sapiens sapiens, el hombre que sabe que sabe. Su conciencia es siempre intencional, es conciencia de, conciencia cargada de contenido, una conciencia volcada hacia el mundo, en relación dialéctica con él ${ }^{5}$. No existe conciencia sin mundo, ni mundo sin conciencia; es decir, sin la presencia de los seres humanos. Mientras que para los animales, la realidad externa que los rodea constituye un mero soporte atemporal; es decir, el aquí no es sino un hábitat con el que contactan, viven sumergidos en la vida, sin posibilidad de emerger de ella, ajustados y adheridos a la realidad, para los hombres y mujeres la realidad circundante se convierte en mundo ${ }^{6}$. Esto se realiza gracias a la capacidad de los seres humanos de actuar sobre ella a partir de unos propósitos, de unos fines determinados, impregnándola de este modo de humanidad, transformándola mediante su praxis, a través de su trabajo. Modificar el mundo es humanizarlo, aunque esto no suponga la humanización de los hombres y mujeres. Puede sencillamente implicar la impregnación del mundo con la presencia creativa del ser humano, pero dicha impregnación puede conducir tanto a la humanización como a la deshumanización, al engrandecimiento del sujeto como ser ético o a su degradación. Ahora bien, ambas alternativas revelan al ser humano su naturaleza

\footnotetext{
${ }^{5}$ La concepción humanista de la conciencia coincide con la de los fenomenólogos: "En lugar de una conciencia 'cosa', la concepción humanista entiende, con los fenomenólogos, la conciencia como un despegarse del hombre hacia el mundo. No es un recipiente que se llena, es un ir hacia el mundo para captarlo. Lo propio de la conciencia es estar dirigida a algo. La esencia de su ser es su intencionalidad intentio, intendere-; de ahí que toda conciencia es siempre conciencia de. Aun cuando la conciencia realiza la vuelta sobre sí misma, 'algo tan evidente y sorprendente como la intencionalidad' (Jaspers) sigue siendo conciencia de. En este caso, conciencia de conciencia; conciencia de sí misma” (Fiori, 1978: 51).

6 "El animal sólo tiene contactos, sólo se adapta al ambiente. El ser humano tiene relaciones, se integra en el contexto. Los contactos propios de la esfera animal implican, contrariamente a las relaciones, respuestas singulares, reflejas y no reflexivas, culturalmente inconsecuentes. De ello resulta el acomodamiento, no la integración. El hombre, en cambio, es un ser integrado. Su lucha viene siendo, a través del tiempo, la de superar los factores que lo hacen acomodado o ajustado" (Freire, La educación como práctica, 32).
} 
problemática, le impulsan a que ejerza su libertad. Los hombres construyen la historia que, a su vez, los constituye ${ }^{7}$. El aquí ya no es sólo un espacio físico como para el resto de los animales, es también un espacio histórico.

Freire distingue entre vivir y existir. Únicamente los seres humanos existen, el resto de los animales sólo viven, idea que hace hincapié en la responsabilidad creadora que tenemos en la construcción de nuestro ser en el mundo, de nuestra personalidad y del contexto en el que vivimos: "Existir es un modo de vida propio del ser que es capaz de transformar, de producir, de decidir, de crear, de comunicarse", dirá el pedagogo brasileño (Acción cultural, 1975: 86-89). La existencia es un plus que el ser humano añade a la vida que le es dada, territorio existencial constituido por el trabajo, la historia, la cultura, los valores, territorio en el cual se experimenta la dialéctica entre los condicionamientos y la libertad. Sabiendo que existen condiciones materiales, económicas, sociales, políticas, culturales e ideológicas que pueden actuar de obstáculos para desempeñar la tarea de transformar el mundo, el sujeto tiene que asumir que dichas barreras no han de ser eternas. Contamos con un mundo de opción, de decisión donde el hombre ha de asumir su responsabilidad ética, histórica, política y social (Freire, Pedagogía da autonomia, 1999: 60).

La situación de estar con el mundo, junto con otras personas, propia del ser humano, es posible gracias a la capacidad de éste de distanciarse objetivamente del mismo. Sin esta objetivación, a través de la cual también se objetiva a sí mismo, el sujeto estaría limitado a ser en el mundo -propia del resto de los animales- careciendo tanto de autoconocimiento como de conocimiento acerca del mundo. Si no fueran capaces de este distanciamiento epistemológico que exige la objetivación, los individuos humanos no podrían superar su adherencia al mundo, no podrían admirarlo como objeto, serían incapaces de captar los condicionamientos económicos, políticos, sociales, culturales, que sufren, y por consiguiente, no podrían superarlos. Esta toma de conciencia de las razones profundas que explican ciertos hechos es lo que Freire llama concientización, palabra clave en su pensamiento, en su pedagogía emancipadora ${ }^{8}$. Y ello es así porque sólo los seres que pueden reflexionar acerca del hecho de que están determinados son capaces de liberarse, de superar las trabas que le impiden ser más, su humanización ${ }^{9}$. Toda la pedagogía de Freire va dirigida a esa emancipación del hombre, tan fuertemente amenazada por los intereses de unos pocos, los poderosos, los opresores, en definitiva, aquellos que trabajan por conseguir que el resto de individuos permanezcan en un estadio de nula o mínima conciencia crítica sobre el mundo, tratándolos como objetos, como

\footnotetext{
7 "Como dijo Marx, la historia no nos dirige, nosotros construimos la historia. La historia nos constituye mientras la construimos(...). Necesitamos ser sujetos de la historia, aún cuando no podamos dejar de ser totalmente objetos de la historia. Y para ser sujetos, necesitamos sin duda dirigirnos críticamente a la historia. Como participantes activos y sujetos reales, sólo podemos construir historia cuando somos permanentemente críticos con nuestras propias vidas" (Freire, Revisión de la pedagogía crítica. Entrevista a Paulo Freire por Donaldo Macedo, en La naturaleza política, 1990: 195).

${ }^{8}$ Sin embargo, Freire no es el creador del término "concientización", como él mismo aclara: "Se cree, generalmente, que soy yo el autor de este extraño vocablo, concientización, debido a que es el concepto central de mis ideas sobre la educación. En realidad, fue creado por un equipo de profesores del Instituto Superior de Estudios del Brasil hacia los años 64. Se puede citar entre ellos al profesor Álvarez Pinto y al profesor Guerreiro. Al oír por primera vez la palabra concientización, me di cuenta inmediatamente de la profundidad de su significado porque estoy absolutamente convencido de que la educación, como práctica de la libertad, es un acto de conocimiento, una aproximación crítica a la realidad. Desde entonces esta palabra entró a formar parte de mi vocabulario. Pero fue Helder Cámara quien se encargó de difundirla y de traducirla al inglés y al francés" (Inodep, 1980: 35).

9 Henry A. Giroux señala al respecto que "lo que subyace al lenguaje de la crítica de Freire es la comprensión de que la historia jamás queda excluida, y de que así como las acciones de las personas se ven limitadas por las restricciones específicas en que se encuentren, son también las personas quienes generan dichas restricciones, igual que las posibilidades que pueden abrirse al desafiarlas" (Introducción a Freire, La naturaleza, 14).
} 
instrumentos para satisfacer sus intereses. El objetivo freireano es dotar a los sujetos de una conciencia crítica que redunde en una praxis transformadora de una realidad social injusta ${ }^{10}$.

De la antropología hemos desembocado en la teoría del conocimiento de Paulo Freire, en la que se hace hincapié en la necesidad de "tomar distancia" como estrategia de aproximación epistemológica cara al conocimiento de un objeto, valga la paradoja. Y es así como aparecen dos tipos de saberes: la docsa, el saber de sentido común, la forma cotidiana de acercamiento al mundo, el conocimiento espontáneo, en el que no se revelan las auténticas razones o causas de los fenómenos, el propio de lo que Freire llamará la conciencia ingenua, y el saber científico, aquel vinculado a una conciencia crítica; saber que aprehende las verdaderas razones, el logos de la realidad, y que obtiene su garantía en la rigurosidad del método ${ }^{11}$. La educación progresista se planteará el paso de una conciencia a otra, por lo que prestará especial atención a la metodología empleada por el docente, que coincide con el método que utiliza la conciencia crítica en su aprehensión de la realidad. Sirvan como referencia las características que a uno y a otro tipo de conciencia adjudica el propio Freire:

\footnotetext{
${ }^{10}$ Precisamente, uno de los cambios más significativos en el pensamiento de Freire reside en el poder otorgado a la concienciación. Con el transcurrir de los años, se da cuenta de que ésta es condición necesaria para la transformación social, pero no suficiente. Él mismo, que continuamente va revisando su pensamiento, se da cuenta de esta falacia inicial, como comenta en algunas de las entrevistas que se le realizaron: "De hecho uno de los aspectos más débiles de mi trabajo, sobre el cual he elaborado una autocrítica, es el proceso de concienciación. En la medida en que en mis primeros trabajos teóricos no hice prácticamente ninguna referencia al carácter político de la educación y desatendí el problema de las clases sociales y su lucha, dejé las puertas abiertas a todo tipo de interpretaciones y prácticas reaccionarias, que llevaron a muchas distorsiones de lo que debe verdaderamente ser la concienciación. (...) Los seres humanos no trascienden la situación concreta, la condición en que se encuentran, únicamente por medio de su conciencia o de sus intenciones, no importa lo buenas que éstas sean. Las posibilidades que yo tenía de trascender los estrechos límites de una celda de dos por uno en la que fui encerrado tras el golpe de Estado de abril de 1964, no eran suficientes para modificar mi condición de prisionero (La naturaleza política, 154156). Estas palabras son fragmentos de una entrevista llevada a cabo en Ginebra en 1973 por el Instituto de Acción Cultural; también en en el capítulo. 13, "Llamada a la concienciación y a la desescolarización" (La naturaleza política, 167). Freire insiste en este apartado: "Creo que debería establecer algunas consideraciones adicionales. Una de ellas implicaría una autocrítica, basada en mi La educación como práctica de la libertad por creer que en el proceso de concienciación el momento de revelación de una realidad social actúa como una especie de motivación psicológica para su transformación. Obviamente, mi error no fue admitir la importancia fundamental del conocimiento del mundo real en el proceso de su transformación. Mi error fue no considerar las polaridades -conocimiento de la realidad y transformación de la realidad- en su dialéctica. Fue como si el descubrimiento de la realidad garantizara que comenzara a transformarse. En la Pedagogía del oprimido y en Cultural Action for Freedom he dicho, como de pasada, que aquella no es mi postura respecto del problema de la concienciación. (...) En función de mi experiencia actual, (...) estoy percibiendo también esta clase de error en algunas de mis actividades tempranas, y en ciertos pedagogos que no ven la dimensión y las implicaciones políticas de su práctica pedagógica. Hablan de una concienciación que es estrictamente pedagógica, distinta de la de los políticos".

${ }^{11}$ En cuanto seres conscientes que somos, tenemos una forma de acercarnos al mundo; yo la llamaría una forma cotidiana de acercamiento al mundo. De ahí la posibilidad de hablar de una cierta alienación de lo cotidiano; en la forma cotidiana de acercarme al mundo, que es una forma espontánea de moverme en el mundo ( $\mathrm{y}$ cuando me muevo en el mundo, me acerco a él), no tengo necesariamente -en términos científicos-, una mente epistemológica; cuando me muevo espontáneamente en el mundo, no tengo al mundo necesariamente como objeto de mi conocimiento crítico; sin embargo, tengo un conocimiento de este mundo, aun cuando no tenga un conocimiento epistemológico de él; este conocimiento espontáneo es de doxa, de opinión, de darse cuenta del mundo (...). Para conocer tengo que sentir, pero cuando mi conocimiento se queda a un nivel preponderante de la sensibilidad de lo conocido, no alcanza la entidad; lo que Marx llamó la razón de ser de la realidad. Esta razón en el lenguaje griego sería el logos de la realidad, en el sentido epistemológico (Freire, "La desmitificación de la concientización" conferencia Cuernavaca, 1971).
} 


\section{a) Conciencia ingenua}

1. Revela una cierta simplicidad tendiente a un simplismo en la interpretación de los problemas, es decir, encara un desafío con tendencia simplista o con simplicidad. No profundiza en la causalidad del hecho mismo. Sus conclusiones son apresuradas, superficiales.

2. Hay también una tendencia a considerar que todo tiempo pasado fue mejor. Por ejemplo, los padres que lamentan la conducta de sus hijos en relación con lo que ellos hacían cuando jóvenes.

3. Tiende a aceptar formas gregarias o masificadoras de comportamiento. Esta tendencia puede llevar a una conciencia fanática.

4. Subestima al hombre sencillo.

5. Es impermeable a la investigación. Se satisface con las experiencias. Toda concepción científica es para ella un juego de palabras. Sus explicaciones son mágicas.

6. Es frágil en la discusión de los problemas. El ingenuo parte de la base de que lo sabe todo. Pretende ganar la discusión con argumentaciones débiles. Es polémico; no pretende esclarecer. Su discusión se nutre más de emocionalidad que de criticidad. No busca la verdad; trata de imponerla y buscar medios históricos para influir con sus ideas. Es curioso ver cómo los oyentes se dejan llevar de los artificios de los gestos y de la palabrería. Trata de pelear más para ganar más.

7. Tiene fuerte contenido pasional. Puede caer en el fanatismo o sectarismo.

8. Presenta fuertes comprensiones mágicas.

9. Dice que la realidad es estática y no cambiante.

\section{b) Conciencia crítica}

1. Anhelo de profundidad en el análisis del problema. No se satisface con las apariencias.

Puede reconocerse desprovista de instrumentos para el análisis de problemas.

2. Reconoce que la realidad es cambiante.

3. Sustituye situaciones mágicas o explicaciones mágicas por principios de causalidad auténticos.

4. Procura verificar o chequear los hallazgos. Está siempre dispuesta a las revisiones.

5. Al enfrentarse a un hecho, hace lo posible por despojarse de prejuicios. No sólo en la captación, sino también en el análisis y en la respuesta.

6. Rechaza posiciones quietistas. Es intensamente inquieta. Es tanto más crítica cuanto más reconoce en su quietud la inquietud y viceversa. Sabe que es en la medida en que es y no por lo que parece. Lo esencial para parecer algo es ser algo; es la base de la autenticidad.

7. Rechaza toda transferencia de responsabilidad y de autoridad, y acepta la delegación de las mismas.

8. Es interrogadora, averigua, impacta, provoca.

9. Ama el diálogo. Se nutre de él.

10.Ante lo nuevo, no rechaza lo viejo por ser viejo, ni acepta lo nuevo por serlo, sino en la medida en que son válidos (Educación y cambio, 1976: 36-37).

Un aspecto particularmente importante en la teoría del conocimiento de Freire es el carácter social que da al proceso de saber. Éste, que envuelve al individuo como un todo, sin falsas dicotomías entre razón y sentimientos, abarca a otros sujetos cognoscentes. "La relación cognoscitiva no concluye en la relación sujeto cognoscente-objeto cognoscible, puesto que se extiende a otros sujetos cognoscentes" (Cartas a quien, 2001: 135). De hecho, sin la relación comunicativa entre sujetos cognoscentes en torno a un objeto cognoscible, desaparecería el acto cognitivo. Freire insiste en que al concebir el 
conocimiento como un hecho acabado, en sí, se pierde la visión dialéctica, única que explica la posibilidad de conocer: "Conocimiento es proceso que resulta de la praxis permanente de los seres humanos sobre la realidad" (Entrevistas con Paulo, Freire, 1978: $63)^{12}$.

Con esta definición de conocimiento, Freire se propone huir de una visión de la sociedad en la que ésta aparece bipolarizada. Si se parte de una concepción del conocimiento como algo concluido y finalizado, se cae en una posición en la que se divide la sociedad en los que poseen este conocimiento y los que no lo poseen. Ahora bien, se puede partir de otra percepción de la realidad, lo que implica otra ideología, la humanizadora, la defendida por Freire: aquella que no separa el conocimiento existente del acto de conocer lo nuevo. Consiste en admitir algo tan obvio como que no hay ningún conocimiento nuevo que no haya nacido de otro conocimiento antes existente y que, a su vez, superó uno que lo antecedía. Este nuevo conocimiento necesita de otro que lo remplace, pues todo conocimiento presente está esperando para ser superado. En definitiva, se apoya la idea de que el conocimiento, en lugar de ser hecho, es un proceso que resulta de la praxis de los seres humanos sobre la realidad que ellos transforman. Admitidas estas proposiciones, no parece legítimo separar a aquellos que saben de aquellos que no saben, transformando a los primeros en poseedores de un conocimiento existente para transferirlos a aquellos que no saben. Conocer es buscar en comunión a través de la praxis que se está analizando ${ }^{13}$.

Para el pedagogo brasileño, todo acto de pensar exige, pues un sujeto que piensa, un objeto pensado, que mediatiza al primero del segundo sujeto, y la comunicación entre ambos, que se da a través de signos lingüísticos. No hay un "pienso", sino un "pensamos"14. Esta coparticipación de los sujetos en el acto de pensar se da en la comunicación. Y la característica esencial de la misma es el diálogo, que se constituye en un término central de la pedagogía freireana. Examinemos algunas de sus notas fundamentales:

En primer lugar, exige un encuentro; requiere que los sujetos interlocutores vuelquen su admiración sobre el mismo objeto, que lo expresen a través de signos lingüísticos, pertenecientes al universo común a ambos, para que así comprendan, de manera semejante, el objeto de la comunicación. Es un encuentro que solidariza la reflexión y la acción de sus sujetos orientadas hacia el mundo que debe ser transformado y humanizado. Asimismo, demanda humildad. Como encuentro de los sujetos para la tarea común de saber y de actuar, se rompe si sus polos -o uno de ellos- pierden la humildad, si se desprecian entre ellos, si caen en la arrogancia. El diálogo supone conciencia de que no existe saber absoluto ni ignorancia absoluta, sino seres humanos que, en comunicación, buscan saber más. Como indica sabiamente Freire:

\footnotetext{
${ }^{12}$ Esta definición, junto con las explicaciones posteriores sobre teoría del conocimiento, formaban parte de "Entrevista con Paulo Freire", publicada en Cuadernos de Educación No. 26 y en Revista de Ciencias, 1973: 50-58.

${ }^{13}$ Freire señala que esto es lo que constituye la unidad entre teoría y práctica. Critica duramente a la Universidad, puesto que observa que las universidades parten de la concepción del conocimiento existente como poseído. De hecho, denomina a las mismas, "casas de transferencia del conocimiento", por la definición del conocimiento y del acto de conocer que apoyan, concepción que beneficia a la burguesía pero que perjudica al proletariado (Entrevistas con Paulo, 63 y 77 ).

${ }^{14} \mathrm{El}$ "yo", la existencia individual, no es explicable partiendo únicamente de la conciencia individual, sin que ello impida que cada ser humano tenga rasgos singulares. De hecho, dicha conciencia ha sido formada en contacto con los otros, de ahí que Freire insista en que es el "nosotros pensamos" el que explica el "yo pienso", es el "nosotros sabemos" el que explica el "yo sé" (Entrevistas con Paulo, 64).
} 
¿Cómo puedo dialogar, si me admito como un hombre diferente, virtuoso por herencia, frente a los otros, meros objetos en quienes no reconozco otros "yo"?

¿Cómo puedo dialogar, si me siento participante de un "ghetto" de hombres puros, dueños de la verdad y del saber, para quien todos los que están fuera son "esa gente" o son "nativos inferiores"? (Pedagogía del oprimido, 107).

El diálogo exige fe en los seres humanos, fe que aparece como un a priori de la comunicación, puesto que apunta a la idea de que entre todos podemos conocer la realidad y, en su caso, transformarla. Basándose en la fe y en la humildad, el diálogo se convierte en una relación horizontal que trae como consecuencia la confianza de los interlocutores ${ }^{15}$. Los sujetos dialógicos se van haciendo cada vez más compañeros en su pronunciación de mundo. Pero para lograr la confianza del otro, es necesario dar muestra de coherencia entre el decir y el hacer, entre las palabras y las acciones. La confianza implica el testimonio que un sujeto da al otro de sus intenciones reales y concretas (Pedagogía del oprimido, 109).

Por último, otro requisito del diálogo es la esperanza. Si a través de ese encuentro interpersonal no se espera nada, si no hay ilusión en mejorar la comprensión del mundo, si no hay perspectiva de optimizar la realidad que nos rodea, si no hay anhelo de crecer como personas y de posibilitar una transformación positiva de nuestra sociedad, de nuestras prácticas sociales gracias a este intercambio de experiencias, de conocimientos, el diálogo no tendría ningún sentido. Cuando se pierde la esperanza, se pierde la palabra, al menos, como praxis -tal como la entiende Freire-. Y es que el diálogo del que habla el pedagogo implica una postura crítica, una preocupación por aprehender la razón de ser del objeto que media entre los sujetos del diálogo, una curiosidad epistemológica.

\section{La educación dialógica y problematizadora freireana}

Este recorrido por la antropología y la teoría del conocimiento defendida por Freire sirve como base firme para entender sus propuestas educativas. La educación toma como base la indeterminación del ser humano, la conciencia que tiene de su finitud, de ser inacabado $^{16}$, que le lleva a estar en una búsqueda constante de ser más, de crecer como persona. En esta búsqueda no está solo; ha de realizarla en comunión con los otros, con otros sujetos que también buscan ser más. La finalidad básica de la educación, para el

\footnotetext{
${ }^{15}$ Freire da la siguiente definición de diálogo: Es una relación horizontal de A más B. Nace de una matriz crítica y genera crítica (Jaspers) Se nutre del amor, de la humildad, de la esperanza, de la fe, de la confianza. Por eso sólo el diálogo comunica. Y cuando los polos del diálogo se ligan así, con amor, esperanza y fe uno en el otro, se hacen críticos en la búsqueda de algo. Se crea, entonces, una relación de simpatía entre ambos. Sólo ahí hay comunicación (La educación como práctica, 104).

${ }^{16}$ I perro y el árbol son también inacabados, pero el hombre se sabe inacabado y por eso se educa. (...) El hombre es un ser en búsqueda constante de ser más y como puede hacer esta autorreflexión se puede descubrir como un ser inacabado, que está en la búsqueda. He aquí la raíz de la educación. (...) La educación, por tanto, implica una búsqueda realizada por un sujeto que es el hombre. El hombre debe ser sujeto de su propia educación. No puede ser objeto de ella. Según esto, nadie educa a nadie. Por otra parte, la búsqueda debe ser algo y debe traducirse en ser más: es una búsqueda permanente de sí mismo. (...) Esta búsqueda debe hacerse con otros seres que también buscan ser más y en la comunión con otras conciencias, porque si no haría a unas conciencias objetos de otras. Sería 'cosificar' las conciencias (Educación y cambio, 21 y 22). Como católico creyente, Freire en algunas de sus obras comenta que la plenitud del ser humano se halla en la unión con el Creador (véase, por ejemplo, La educación como práctica de la libertad, cap. 1), pero en otras, omite esta referencia, quizás convencido de que sus propuestas no exigen como condición imprescindible ser creyente. De hecho, en A la sombra de un árbol, comenta que no se siente cómodo hablando de su fe, a pesar de que siempre le ha dado aliento en su vida (115 y 116).
} 
pedagogo brasileño, es conseguir una persona capaz de poseer un conocimiento cierto sobre la realidad en la que vive y poder transformarla orientándola hacia valores como la paz, la justicia social, la cooperación, la solidaridad, la tolerancia. Valores que sostienen la ética humanista que Freire abraza. Forjar un sujeto capaz de un pensar crítico que dé lugar a la acción, sentido del término praxis. Ahora bien, esta meta es perseguida por la educación auténtica, por la progresista, por la problematizadora, defendida por el pensador latinoamericano. Las prácticas educativas que encuentra más generalizadas, de hecho, las predominantes en Brasil en donde comienza su trabajo profesional, poco tienen que ver con la misma. Se imparte una educación que en vez de humanizar, deshumaniza: la educación bancaria.

En la concepción bancaria de la educación, el saber se piensa como si fuera un alimento que el educador va introduciendo en los educandos, en una especie de tratamiento que engorda, y correspondería a lo que Sartre llama, en El hombre y las cosas, concepción digestiva o alimenticia del saber ${ }^{17}$. La educación se convierte en transferencia de conocimientos del que sabe al que no sabe. La realidad aparece como algo detenido, estático, cualidades que permiten obtener de ella un conocimiento cerrado, completo. Es ese conocimiento el que posee el educador, cuya tarea es llenar a los educandos -vistos como depósitos, como vasijas- de contenidos. El educador no comunica, en el sentido dialógico del que hemos hablado, sino hace comunicados, hecho sólo posible debido a la consideración de los educandos como meros objetos, como instrumentos cuya única función es la de recibir los depósitos, guardarlos y archivarlos. En esta forma de concebir la educación, el saber, el conocimiento es una donación de aquellos que se juzgan sabios (educadores) a los que se juzgan ignorantes (educandos). Las prácticas educativas no están destinadas al logro de una conciencia crítica por los educandos, a que se conciban como seres con el mundo, capaces de transformarlo, sino a que permanezcan en una percepción ingenua de la realidad, en la que no asumen su papel creador, de tal forma que se limitan a adaptarse, a ser simples espectadores pasivos de los acontecimientos. La conciencia de los discentes es concebida como algo espacializado, vacío, que va siendo llenado con pedazos del mundo digeridos por otros.

Las principales características de la educación bancaria se resumen en las siguientes ${ }^{18}$ :

a) El educador es siempre quien educa; el educando, el que es educado.

b) El educador es quien disciplina; el educando, el disciplinado.

c) El educador es quien habla; el educando, el que escucha.

d) El educador prescribe; el educando sigue la prescripción.

e) El educador elige el contenido de los programas; el educando lo recibe en forma de depósito.

f) El educador es siempre quien sabe; el educando, el que no sabe.

g) El educador es el sujeto del proceso; el educando, su objeto.

Frente a ella, está la educación liberadora, aquella entendida como praxis, reflexión y acción del ser humano sobre el mundo para transformarlo. Aquella con base en el diálogo, que no da recetas ni dogmas, sino que problematiza. Educación a la que apeló Freire desde los primeros momentos en su trabajo con la alfabetización de adultos en Brasil, planteada hasta entonces como un bla-bla-bla sin sentido, alejada de la vida real de los analfabetos. Porque él siempre tuvo presente que la lectura de la palabra tenía que ir

\footnotetext{
${ }^{17}$ La influencia de Sartre en el pensamiento freireano es clara, tanto en su concepción de la existencia como construcción del ser humano, como en la de educación. Es el mismo Freire el que menciona el libro El hombre y las cosas en nota a pie de página (Pedagogía del oprimido, 83).

${ }^{18} \mathrm{La}$ "concepción bancaria" de la educación es una expresión que Freire recoge de Furter. Estas características aparecen mencionadas en el prólogo de Julio Barreiro (La educación como práctica, 17). 
unida a la lectura crítica de la realidad, y de hecho, esta última tenía precedencia. Convicción que, por otra parte, le causaría graves problemas en su propio país, que le obligarían a sufrir el exilio durante la dictadura militar que comenzó en 1964, y más tarde en Chile, de nuevo con gobiernos militares. No convenía a los intereses dominantes que las clases populares adquirieran la palabra, que se asumieran como seres de praxis. Resultaba incómodo para las clases poderosas un hombre que trabajase en convertir a los más débiles, a los más oprimidos, en auténticos ciudadanos, en sujetos capaces de enjuiciar críticamente la realidad y de participar en su construcción más justa, más humana. Ahora bien, ni los exilios, ni las críticas, ni las penurias lograron acallar la voz de aquel que defendió el dar la voz, el dar la palabra a los más desfavorecidos, porque ésa, siempre dirá, es la responsabilidad ético-política de todos los seres humanos, y mucho más de quien se declara educador. Porque ese dar la palabra es capacitar para expresar la percepción original, propia, del mundo, y es una palabra que abre las puertas para la acción. Por eso es praxis.

Muchas son las obras que nos hablan de este compromiso de Freire y de su propuesta de educación liberadora, problematizadora, desde las primeras como La educación como práctica de la libertad (1967) y Pedagogía del oprimido (1970), que le abrieron las puertas a nivel internacional, pues fue invitado a dar múltiples conferencias para explicar sus ideas, hasta sus últimos trabajos, como Pedagogía de la esperanza (1992), Cartas a Cristina (1994) o Pedagogía de la indignación (2001), que dejó inconclusa, pues le sorprendió la muerte cuando sólo llevaba tres cartas de lo que iba a ser una colección que titularía Cartas Pedagógicas ${ }^{19}$. A la hora de exponer la teoría educativa de Freire, nos centraremos especialmente en Cartas a quien pretende enseñar (1993) y en Pedagogía de la autonomía (1996), a pesar de que no dejemos de establecer conexiones con el resto de sus obras. Se han elegido estas dos debido a que ambas han sido escritas cuando ha transcurrido la mayor parte de la vida de Freire y, por consiguiente, ha re-pensado, revisado una y otra vez sus planteamientos. Como obras de madurez, nos revelan las principales conclusiones vitales a las que ha llegado el pedagogo brasileño relacionadas con el mundo educativo. Además, otros argumentos apoyan nuestra elección. Pedagogía de la autonomía es considerada por algunos críticos de Freire como su libro testamento ${ }^{20}$. Cartas a quien pretende enseñar, es el único libro que el pensador latinoamericano dirige directamente a los maestros, y más en concreto a las maestras, de la escuela regular, tocando un tema tan candente en la actualidad como la profesionalización docente.

En la teoría pedagógica freireana, la educación va a ser considerada como práctica de la libertad. Ello exige detenernos primeramente en el proceso de enseñanza-aprendizaje, un proceso muy distinto al que defiende la educación bancaria, basado en la antropología y en la teoría del conocimiento que hemos expuesto. Enseñar, para Freire, no consiste en un simple proceso de transferencia de conocimientos del educador al aprendiz, transmisión mecánica de la que resulta la memorización mecánica. La enseñanza, para el brasileño, tiene como principal misión crear las posibilidades para la producción o la construcción del conocimiento, y el educando tiene que experimentarlo, tiene que vivirlo. Es decir, Freire huye de una concepción en la que el formador aparece como el sujeto en relación con el cual el educando se considera el objeto, la concepción bancaria. Según sus planteamientos, quien forma se re-forma al educar y quien es formado se educa a sí mismo (y al formador): "Quien enseña aprende al enseñar y quien aprende enseña al aprender" (Pedagogía de la autonomía, 25). El aprendizaje válido existe cuando el aprendiz se torna capaz de recrear y rehacer lo enseñado. Cuanto más críticamente se

\footnotetext{
${ }^{19}$ reire murió el 2 de mayo de 1997. La tercera carta comprende las últimas palabras escritas por Freire el 21 de abril de ese mismo año, según nos aclara su segunda esposa, Ana María Araújo, quien se encargó de recopilar el material para que saliera a la luz.

${ }^{20}$ Así lo indica Balduino A. Andreola en la carta-prefacio que aparece en Pedagogía de la indignación.

Digitalizado por RED ACADEMICA
} 
ejerza la capacidad de aprender, tanto más se desarrolla la llamada curiosidad epistemológica, sin la cual no alcanzamos el conocimiento cabal del objeto. En lo que respecta al educador, aprende porque, por un lado, re-conoce un conocimiento antes aprendido; es decir, repiensa lo pensado, revisando así sus posiciones, y, por el otro, porque observando la manera como la curiosidad del alumno trabaja para captar lo que se le está enseñando, se ayuda a mejorar su labor como educador, a optimizar los métodos empleados en su clase, su organización del currículo. Es en esta línea en la que Freire habla de educadores-educandos y de educandos-educadores.

Considerando que el fin de la educación es capacitar a los seres humanos para la praxis, para la reflexión y la acción sobre el mundo, se entiende que el enseñar y el aprender se relacionen, para Freire, con el esfuerzo metódicamente crítico del docente de develar la comprensión de algo y con el empeño igualmente crítico del discente de ir penetrando como sujeto en el aprendizaje, en un proceso de develamiento facilitado por el educador. Una de las tareas principales de educador progresista es apoyar al educando para que él mismo venza sus dificultades en la comprensión del objeto, y para que su curiosidad, compensada y gratificada por el éxito del entendimiento alcanzado, sea mantenida y estimulada a continuar la búsqueda permanente que el proceso de conocer implica. Freire insiste en que enseñar no es transferir la comprensión del objeto al educando, sino instigarlo en el sentido de que, como sujeto cognoscente, se torne capaz de comprender $y$ comunicar lo comprendido (Pedagogía de la autonomía, 134). Para ello, el educador debe escuchar al educando en sus dudas, en sus interrogantes, en su incompetencia provisional. Escuchándolo, aprende a hablar con él, aprende la difícil lección de transformar su discurso, las veces necesarias, en un habla con el alumno.

Freire defiende la importancia del diálogo del maestro con los educandos, un diálogo que no es sólo de los contenidos curriculares, sino sobre la vida misma, y que es creador de un ambiente abierto y libre en el seno de la clase. Este hablar a y con los educandos es una forma de contribuir a la formación de ciudadanos responsables y críticos, necesarios para una auténtica democracia. Es un diálogo que recoge las características antes mencionadas de: encuentro, relación horizontal, curiosidad epistemológica, humildad, fe en los seres humanos, confianza y amor. Es conveniente resaltar que -subraya el brasileño- el diálogo entre profesores y alumnos no los convierte en iguales, no nivela, pero señala la posición democrática entre ellos. Si fuesen iguales, uno se convertiría en otro. Freire mantiene que el diálogo gana significado precisamente porque los sujetos dialógicos no sólo conservan su identidad, sino que la defienden y así crecen uno con el otro. Implica siempre un respeto de los sujetos involucrados en él.

Todas estas características nos revelan el hecho fundamental de que la educación es un acto político: todo acto educativo tiene naturaleza política y todo acto político posee naturaleza educativa ${ }^{21}$. Al igual que no existe la llamada neutralidad de la ciencia -mito positivista-, tampoco existe la neutralidad de la educación. Ni la imparcialidad de los científicos ni la de los educadores, debido a que no hay ninguna acción humana desprovista de intención, de objetivos. No hay ningún ser humano ahistórico, ni apolítico. No significa, sin embargo, que debamos confundir la no neutralidad de la ciencia, de la educación, con la falta de rigor sistemático, serio, profundo, en la búsqueda de la verdad, de la humanización del hombre. Son cosas completamente distintas.

Es preciso hacer hincapié en que el elemento político de la educación es independiente de la subjetividad del educador; es decir, de que éste sea consciente de dicho factor. El docente jamás es neutral. Como bien dice Freire: "Toda neutralidad afirmada, es una

\footnotetext{
${ }^{21}$ Se entiende por "política", la dirección racional y activa de cualquier proceso social (Educación liberadora,
} 28). 
opción escondida" (Entrevistas con Paulo, Freire, 71) ${ }^{22}$. De ahí la necesidad de que el educador se pregunte para qué o para quién trabaja, a favor de qué intereses, en contra de qué ideologías, puesto que como docentes, lo que debemos hacer es "dejar claro que la educación tiene carácter político, y ser coherentes con ello en la práctica" (Freire y Macedo, Alfabetización, 1987: 59). Freire explicita cuál es su opción: la de la sociedad democrática.

Aquí es preciso señalar la superación que supone la propuesta freireana de las aportaciones ofrecidas por lo que se ha llamado la nueva sociología de la educación o sociología crítica de la educación, que puso en primer plano el papel de la escuela como agente de reproducción social, económica y cultural. A través de ella, estos sociólogos críticos detectaron cómo se inculcaba en los discentes un conjunto específico de códigos y experiencias de la clase dominante. Son ideas que guardan gran similitud con el análisis crítico y con los principios teóricos fundamentales que maneja Freire desde sus primeros trabajos en el plano de la alfabetización de adultos. Él mantuvo que las formas tradicionales de educación funcionaban principalmente para cosificar y alienar a los grupos sometidos, reproduciendo la cultura dominante. Mediante prácticas sociales y textos específicos se producía y mantenía una "cultura del silencio" entre los campesinos brasileños.

Sin embargo, hay una diferencia significativa entre el trabajo de Freire y la nueva sociología de la educación que para mí tiene especial atractivo. Esta última parecía comenzar y concluir en la lógica de la reproducción política, económica y cultural. Para Freire, ésta es sólo el punto de partida, pero no ha de ser el de llegada. Da un paso hacia adelante que resulta fundamental para cualquier educador que crea en la posibilidad de un mundo mejor. La nueva sociología de la educación, con su lenguaje únicamente de crítica, no aportaba esperanza, no ofrecía caminos de salida para una situación que, por su dinámica, tendería a perpetuarse hasta el infinito. Dicho discurso no convence a Freire. Imbuido por el espíritu de la teología de la liberación, piensa que hay que hablar el lenguaje de la posibilidad. Otro mundo es posible, otra educación es posible.

Cierto es que no podemos pensar en la educación sin considerar la cuestión del poder, no podemos comprenderla como práctica neutra. Ahora bien, ello no significa que la educación sistemática sea únicamente una réplica de la ideología dominante. Las relaciones que existen entre la educación y los sub y macrosistemas son relaciones dinámicas, contradictorias y no mecánicas. Las contradicciones que caracterizan a la sociedad tal cual es ahora, penetran en la intimidad de las instituciones pedagógicas en las que opera la educación sistemática y modifican su rol o su tarea de portavoces de la ideología dominante (Alfabetización, 58-59) ${ }^{23}$. La posibilidad de ruptura, de negación de

\footnotetext{
${ }^{22}$ Las ideas comentadas están extraídas de la "Entrevista con Paulo Freire", publicada en Cuadernos de Educación No. 26 y en Revista de Ciencias, 50-58.

${ }^{23}$ Señalo dos ejemplos aportados por Apple que son ilustrativos de estas contradicciones: "En el aparato del Estado las escuelas desempeñan importantes tareas en la creación de condiciones para la acumulación del capital (escogiendo, seleccionando y certificando un grupo de estudiantes organizado jerárquicamente) y para la legitimación (manteniendo una ideología meritocrática falsa y además legitimando formas ideológicas para la recreación de la desigualdad). Con todo, estas dos funciones de la escuela a menudo están enfrentadas. La necesidad de acumular capital puede contradecir la necesidad de legitimación, una situación que actualmente es más conflictiva. En la escuela podemos verlo en la relativa superproducción de individuos cualificados justo en un momento en que la economía no demanda tanto personal altamente remunerado. Esta superproducción cuestiona la legitimidad de los modos de funcionamiento de las escuelas. A un nivel más concreto, podemos ver las contradicciones de las instituciones en el hecho de que la escuela tiene diferentes obligaciones ideológicas que pueden entrar en conflicto. Se necesita capacidad crítica para mantener dinámica nuestra sociedad; por tanto las escuelas enseñarían a los estudiantes a ejercer la crítica. A su vez las capacidades críticas pueden desafiar el capital. Esta no es una idea abstracta. Digitalizado por RED ACADEMICA
} 
esa función reproductora de tal ideología, viene dada por la confrontación concreta con la realidad vivida por los educandos y los educadores, quienes no son receptores pasivos de los contenidos oficiales. Lo más normal es la reinterpretación o como mucho la aceptación parcial, y en algunos casos hasta el rechazo directo a la planificación ideada por las instancias poseedoras del control de la política educativa (Apple, 1982: 30). Esta situación es la que abre las puertas a que, aunque la ideología que se quiere imponer a través de la legislación y de ciertos discursos teóricos por parte de los sectores en el poder, juegue en contra de los principios democráticos, propios del educador progresista, haya alternativas para plantarle cara.

En definitiva, Freire propone una educación para la decisión, para la responsabilidad social y política, que nos haga reflexionar sobre el papel que tenemos en la construcción y en el perfeccionamiento de la democracia (La educación como práctica, 1967: 85). Una educación que nos lleve a ser conscientes de que es posible transformar la realidad, de que es posible vencer el fatalismo que promueven las opciones conservadoras. Su pedagogía es una llamada a la utopía, a la tarea de formular propuestas de posibilidad, de no conformarse pensando que la realidad siempre será así, tal como aparece en el presente.

\section{Competencias del educador y compromiso social}

¿Qué cualidades van a ser imprescindibles en este educador progresista, en este docente comprometido por la causa democrática? Humildad, amorosidad, valentía, tolerancia, decisión, seguridad, tensión entre paciencia e impaciencia y alegría de vivir. No pocas, no fáciles de conseguir, no cómodas en muchos casos, pero, ¿quién dijo que la empresa democrática fuera una tarea sencilla ${ }^{24}$ Freire entiende estas cualidades como predicados que se van generando en cohesión con la opción política de naturaleza crítica del educador.

La humildad supone el reconocimiento de que todos sabemos algo y todos ignoramos algo. Sin ella, difícilmente escucharemos a alguien al que consideramos demasiado alejado de nuestro nivel de competencia. Ahora bien, esta humildad que nos llevaría a escucharlo, no puede ser entendida como un acto de condescendencia de nuestra parte, ese "soy tan bueno que te escucho". Al respecto, comenta Freire: "Escuchar con atención a quien nos busca, sin importar su nivel intelectual, es un deber humano y un gusto democrático nada elitista" (Cartas a quien, 61). De hecho, no se puede conciliar la adhesión a la democracia con la arrogancia, con el engreimiento: ¡Cómo es posible escuchar al otro, cómo dialogar, si la persona sólo se ve a sí misma! Asimismo, si siendo humilde, el educador no se minimiza ni acepta que le humillen -que no es deseable- está siempre abierto a enseñar y aprender. La humildad le ayuda a no dejarse encerrar en el circuito de su verdad. Hay una frase particularmente bella de Freire que contiene esta idea: "La humildad florece en la seguridad insegura de los cautos" (Cartas a quien, 61). Se trata de la certeza incierta, que evita la aceptación de una verdad demasiado segura de sí misma. Es una certeza que se cuestiona a sí misma, que se problematiza, que se revisa. Defiende una postura opuesta a la del autoritario, que, desde su sectarismo,

\footnotetext{
Estos conflictos ideológicos impregnan nuestras instituciones educativas y tienen lugar cada día en ellas" (1982: 30-31).

24 "Realmente es difícil hacer democracia. Es que la democracia, como cualquier sueño, no se hace con palabras descarnadas y sí con la reflexión y con la práctica. No es lo que digo lo que dice que soy un demócrata o que no soy racista o machista, sino lo que hago. Es preciso que lo que hago no contradiga lo que digo. Es lo que hago lo que habla de mi lealtad o no hacia lo que digo" (Cartas a quien, 101).

Digitalizado por RED ACADEMICA
} 
piensa que la suya es la única verdad que necesariamente debe ser impuesta a los demás: es en su verdad donde radica la salvación de los demás. Su saber es iluminador de la oscuridad o de la ignorancia de los otros que, por lo mismo, deben estar sometidos al saber y a la arrogancia del autoritario.

La amorosidad del educador no sólo está dirigida a los alumnos, sino al propio proceso de enseñar. Es un "amor armado", como diría el poeta Tiago de Melo, un amor luchador de quien se afirma en el derecho o en el deber de denunciar las injusticias, de anunciar órdenes sociales más justos y libres, más humanos. Ésta es la forma de amar que, señala Freire, todos hemos de aprender y vivir. Junto a esa valentía de amar, el brasileño coloca la valentía de luchar. Una valentía que es superación del miedo, de temores concretos y a su vez, normales, que sobrevienen cuando el individuo, el educador, es consciente de muchas de las situaciones en las que está inmerso ${ }^{25}$ : miedo a perder el empleo o a no alcanzar cierta promoción por su opción política-pedagógica, miedo a ser tachado de ingenuo por hablar de luchar contra la corrupción, etc. Sentir miedo como tal no es negativo: es humano, es normal. Lo terrible es que ese miedo llegue a paralizarnos. De ahí que sea importante gobernar el miedo, educar el miedo, de donde nace finalmente la valentía. Es necesario continuar la lucha en defensa de los ideales democráticos buscando tácticas que disminuyan el riesgo. Freire nos da una magnífica lección de vida cuando comenta que asumir el miedo es no huir de él sino analizar su razón de ser, medir la relación entre lo que lo causa y nuestra capacidad de respuesta. Asumir el miedo es no esconderlo, única forma de poder vencerlo. Para sobreponerse de él, hay que ser capaz de luchar ${ }^{26}$.

Sin la tolerancia, es inviable una experiencia democrática auténtica, un trabajo pedagógico serio. Hay que entender bien el sentido de esta palabra. No significa ponerse en connivencia con lo intolerable, encubrir lo intolerable, soportar la presencia no muy deseada de mi contrario. No puede ser invocada para justificar atentados a los valores supremos de la persona, a veces amparada en la cobardía a enfrentarse a los fuertes y poderosos en perjuicio de los más débiles ${ }^{27}$. La tolerancia es la virtud que nos enseña a

\footnotetext{
${ }^{25}$ A medida que tengo más y más claridad sobre mi opción, sobre mis sueños, que son sustantivamente políticos y adjetivamente pedagógicos, en la medida en que reconozco que como educador soy un político, también entiendo mejor las razones por las cuales tengo miedo y percibo cuánto tenemos aún por andar para mejorar nuestra democracia. Es que al poner en práctica un tipo de educación que provoca críticamente la conciencia del educando, necesariamente trabajamos contra algunos mitos que nos deforman. Al cuestionar esos mitos también nos enfrentamos al poder dominante, puesto que ellos son expresiones de ese poder, de su ideología" (Cartas a quien, 63).

${ }^{26}$ Freire considera que la lucha de los profesores en defensa de sus derechos y de su dignidad debe ser entendida como un momento importante de su práctica docente, en cuanto práctica ética. No es algo que esté fuera de su actividad docente (Pedagogía da Autonomia, 74). Y llama a la unión de los educadores en la defensa de los mismos: "No veo otra salida que no sea la unidad en la diversidad de intereses no antagónicos de los educadores y de las educadoras en la defensa de sus derechos. Derecho a su libertad docente, derecho a hablar, derecho a mejorar condiciones de trabajo pedagógico, derecho a un tiempo libre remunerado para dedicarse a su permanente capacitación, derecho a ser coherente, derecho a criticar a las autoridades sin miedo a ser castigadas -a lo que corresponde el deber de responsabilizarse por la veracidad de sus críticas-, derecho a tener el deber de ser serios, coherentes, a no mentir para sobrevivir. Es preciso que luchemos para que estos derechos sean más que reconocidos -respetados y encarnados-. A veces es preciso que luchemos junto al sindicato y a veces contra él si su dirigencia es sectaria, de derecha o de izquierda. Pero a veces también es preciso que luchemos como administración progresista contra las rabias endemoniadas de los retrógrados, de los tradicionalistas entre los cuales algunos se juzgan progresistas y de los neoliberales para quienes la historia terminó en ellos" (Cartas a quien, 70-71).

éase, por ejemplo, el temor de ciertas naciones europeas a enfrentarse a ciertas acciones estadounidenses que suponen una injerencia inadmisible en el gobierno de países menos poderosos, muchos de ellos del Tercer Mundo.
} 
convivir con lo que es diferente, a aprender con lo diferente, a respetar lo diferente ${ }^{28}$. Definición que valora positivamente la diversidad, la cultura de ese que no soy yo pero con el que comparto la característica esencial de la humanidad. Implica, además, establecer límites, principios que deben ser respetados: no todo vale ${ }^{29}$. La tolerancia supone respeto, disciplina, ética. Es, ante todo, el reconocimiento de los derechos universales de la persona y de las libertades fundamentales de los demás. En un mundo marcado por la desigualdad, es una actitud constructiva en defensa de la libertad ajena, de su dignidad como persona.

Cualidades estrechamente conectadas en el educador progresista, en opinión de Freire, son la decisión, la seguridad, la tensión entre la paciencia y la impaciencia, y la alegría de vivir.

La capacidad de decisión, totalmente necesaria para el docente, exige tener una buena competencia profesional. La indecisión es interpretada por los educandos como debilidad moral o como incompetencia profesional. El educador democrático no puede caer en el error de anularse bajo la justificación de que en eso demuestra su carácter democrático: si bien no puede asumir solo la vida de su clase, tampoco puede, en nombre de la democracia, huir de su responsabilidad de tomar decisiones. Lo que no puede es ser arbitrario en las decisiones que toma. Al respecto, hay que apuntar que Freire está tanto en contra del laissez-faire del activismo espontaneísta, como del autoritarismo ${ }^{30}$. El docente no puede renegar de su deber de dirigir, de organizar, de planificar las clases, tiene que asumir su deber como autoridad ${ }^{31}$. Otra cosa distinta es que desee hacerlo él solo en toda ocasión, sin dar opción a otros miembros de la comunidad educativa. Hay momentos para compartir la toma de decisiones y momentos para asumirla completamente de forma individual (Cartas a quien, 66). Pero no olvidemos que se aprende a decidir, decidiendo, por lo que hay que enseñar a hacerlo, dándoles oportunidades a los alumnos y mostrando cómo se debe hacer, valorando los pro y los contra de las diferentes alternativas. Es la capacidad de decisión la que nos lleva a ser autónomos ${ }^{32}$.

La indecisión delata falta de seguridad. Y la seguridad es indispensable para quien tenga la responsabilidad del gobierno, sea de una clase, de la familia, de una institución, etc. Ella requiere competencia científica, claridad política e integridad ética. Es esencial constatar el valor que da Freire a estas tres exigencias:

\footnotetext{
${ }^{28} \mathrm{n}$ la Declaración de Principios sobre la Tolerancia, aprobada por la Unesco en el marco de su cincuenta aniversario (1945-1995), se aporta la siguiente definición del término: "La tolerancia es el respeto, la aceptación y la estima de la riqueza y diversidad de las culturas de nuestro mundo, de nuestras formas de expresión y de nuestras maneras de manifestar nuestra cualidad de seres humanos".

${ }_{29} \mathrm{M}$. Trimarchi defiende la necesidad de poner límites a la tolerancia, que estarían representados por el respeto a los derechos humanos. De otro modo, la tolerancia podría justificar el atentado a la propia dignidad (1994: 5).

${ }^{30}$ Para el pedagogo brasileño, autoridad y libertad se dan la mano. El autoritarismo y la licenciosidad son rupturas del equilibrio tenso entre autoridad y libertad. El autoritarismo es una ruptura a favor de la autoridad contra la libertad, y la licenciosidad, una ruptura a favor de la libertad contra la autoridad. Autoritarismo y licenciosidad son formas indisciplinadas de comportamiento que niega lo que él llama vocación ontológica del ser humano (Pedagogía da autonomia, 99).

31 "El testimonio de no asumir su deber como autoridad, dejándose caer en la licencia, es sin duda más funesto que el de extrapolar los límites de su autoridad" (Cartas a quien, 66). Asimismo, en Pedagogía da Autonomia, Freire señala que es obligación del profesor poner límites a la libertad del alumno, él no puede huir de su deber de enseñar, de estar presente en la experiencia formadora del educando de manera respetuosa (66).

32 Én este sentido que uma pedagogía da autonomia tem de estar centrada em experiencias estimuladoras da decisâo e da responsabilidade, vale dizer, em experiencias respeitosas da libertade" (Pedagogía da autonomia, 121). 
No puedo estar seguro de lo que hago si no sé cómo fundamentar científicamente mi acción o si no tengo por lo menos algunas ideas de lo que hago, por qué lo hago y para qué lo hago. Si sé poco o nada sobre a favor de qué o de quién, en contra de qué o de quién hago lo que estoy haciendo o haré. Si esto no me conmueve para nada, si lo que hago hiere la dignidad de las personas con las que trabajo, si las expongo a situaciones bochornosas que puedo y debo evitar, mi insensibilidad ética, mi cinismo me contraindican para encarnar la tarea del educador (Cartas a quien, 67).

Respecto a la primera, la competencia profesional, Freire hace hincapié en la necesidad de que el docente se tome muy en serio su formación, el estudio, la tarea de clase, y habla de la importancia de un aprendizaje constante, de un reciclaje permanente comentando que los educadores deben reivindicar el derecho a un tiempo libre y remunerado para dedicarse a su continua capacitación- (Cartas a quien 29). Sin dicha competencia, el docente no puede tener autoridad en su clase. Ahora bien, ésta debe ir acompañada de claridad política e integridad ética. Un testimonio que nunca ha de faltar en sus relaciones con los alumnos es el de la permanente disposición a favor de la justicia, de la libertad y del derecho a ser. Ni puede eludir su entrega a la defensa de los más débiles sometidos a la explotación de los más fuertes, a la crítica constante de las desviaciones de los caminos correctos. Se trata de mostrar al alumnado la belleza que existe en la lucha ética. El educador progresista sabe que no es un mero docente, no es un simple enseñante. Su tarea no se agota en la enseñanza de las matemáticas, de la geografía o de la historia: exige un compromiso y una actitud a favor de la superación de las injusticias sociales; es un militante político, precisamente porque es maestro (Cartas a quien, 87). El educador no esconde su opción política a su alumnado, pero no la impone. Argumenta su elección, mas presenta otras alternativas ${ }^{33}$.

Estas afirmaciones hablan de la importancia de que el educador dé testimonio de sus ideas con su práctica. Freire reivindica la fuerza del ejemplo, el poder de la coherencia entre el discurso teórico y el práctico, en la formación del educando (Pedagogía de la esperanza, 82). Entre el testimonio del decir y el del hacer, es más fuerte este último porque tiene o puede tener efectos inmediatos. Sin embargo, lo peor para la formación del educando es que frente a la contradicción entre el discurso teórico y la práctica del docente, el educando tiende a no creer lo que el educador dice. Suele pensar: "Si esta cosa que se proclama pero al mismo tiempo se niega tan fuertemente en la práctica fuese realmente buena, no sería sólo dicha sino vivida". Enseñar exige, pues, una corporización de las palabras por el ejemplo.

El educador ha de enfrentarse a la tensión permanente entre la paciencia y la impaciencia. Ni una ni otra en solitario. La paciencia por sí sola puede llevar al educador a posiciones de acomodación, de espontaneísmo, con lo que niega su ideal democrático. Puede conducir a la inmovilidad, a la falta de acción. La impaciencia por sí sola puede llevar al activismo ciego, irresponsable. En el acto de asumir esta tensión está implicada la parsimonia verbal, el control de lo que se habla, la realización de un discurso ponderado pero enérgico ${ }^{34}$.

\footnotetext{
33 "Respetar a los educandos, (...), no significa mentirles sobre mis sueños, decirles con palabras o gestos o prácticas que el espacio de la escuela es un lugar 'sagrado' donde solamente se estudia, y estudiar no tiene nada que ver con lo que ocurre en el mundo de afuera; ocultarles mis opciones, como si fuera 'pecado' preferir, optar, romper, decidir, soñar. Respetarlos significa, por un lado, darles testimonio de mi elección, defendiéndola; por el otro, mostrarles otras posibilidades de opción mientras les enseño, no importa qué" (Pedagogía de la esperanza, 74).

${ }^{34}$ El discurso y la práctica benevolente del que es sólo paciente en la clase hace pensar a los educandos que todo o casi todo es posible. (...) El discurso nervioso, arrogante, incontrolado, irrealista, sin límite, está Digitalizado por RED ACADEMICA
} 
Virtud fundamental para la práctica educativa democrática es la alegría de vivir, que supone, para Freire, una entrega a la vida, a la esperanza ${ }^{35}$. Es una entrega que, sin esconder la existencia de razones para la tristeza en esta vida, prepara para estimular y luchar por la alegría en la escuela. Implica vivir todas las cualidades citadas: humildad, amorosidad, valentía, tolerancia, competencia profesional, capacidad de decidir, seguridad, ética, justicia, tensión entre la paciencia y la impaciencia, parsimonia verbal. Sólo así se llega a ese modelo de escuela alegre, una escuela que el pedagogo caracteriza como:

La escuela que es aventura, que marcha, que no le tiene miedo al riesgo y que por eso mismo se niega a la inmovilidad. La escuela en la que se piensa, en la que se actúa, en la que se crea, en la que se habla, en la que se ama, se adivina la escuela que apasionadamente le dice sí a la vida. Y no a la escuela que enmudece y me enmudece (Cartas a quien, 70).

Todas estas cualidades del educador progresista conducen a la consecución de las condiciones idóneas para el auténtico aprendizaje crítico, objetivo freireano. ¿Cuál es la dinámica de clase que propone el pedagogo brasileño? El docente ha de enseñar a pensar reflexivamente, enseñar no sólo conocimientos, sino a producirlos, enseñar a investigar. La capacidad de observar, de comparar, de evaluar para escoger, mediante la decisión, se convierte en competencia fundamental. Freire aconseja respetar los saberes que posean los educandos, situándolos en el punto de partida ${ }^{36}$. Estos contenidos han de ser aprovechados para discutir la razón de ser de muchos de ellos en relación con los incluidos en nuestros programas de clase. El objetivo es establecer una intimidad entre los saberes curriculares básicos para los alumnos y la experiencia social que ellos tienen como individuos (Pedagogía da Autonomia, 34) ${ }^{37}$. Se trata de que constaten la funcionalidad de lo aprendido, la valía para resolver problemas de la vida cotidiana, en definitiva, se busca que la escuela se acerque a la vida. La institución educativa es un espacio idóneo para constituir el contexto teórico, de reflexión, donde se examinan los temas candentes en el contexto práctico: allí se estimula el distanciamiento epistemológico que lleva al conocimiento auténtico del objeto. Y es que el docente ha de procurar que el alumno pase de la ingenuidad a la criticidad en el conocimiento de situaciones y fenómenos. Una criticidad que aparece como resultado de la aplicación de procedimientos metodológicamente rigurosos. Una criticidad que surge fruto de una

\footnotetext{
empapado de inconsecuencia, de irresponsabilidad. Estos discursos no ayudan en nada a la formación de los educandos" (Pedagogía de la esperanza, 69).

${ }^{35}$ Freire establece una estrecha conexión entre la alegría que debe impregnar el proceso educativo y la esperanza, que a su vez se relaciona con la antropología que maneja: "Hay una relación entre la alegría necesaria a la actividad educativa y la esperanza. La esperanza de que profesor y alumnos, juntos, podemos aprender, enseñar, inquietarnos, producir y juntos igualmente resistir a los obstáculos a nuestra alegría. En verdad, desde el punto de vista de la naturaleza humana, la esperanza no es algo que a ella se yuxtaponga. Sería una contradicción que, inacabado y consciente de su inacabamiento, primero, el ser humano no se inscribiese o no se hallase predispuesto a participar en un movimiento constante de busca, y, segundo, se buscase sin esperanza. La desesperanza es negación de la esperanza. (...) Sin esperanza no habría Historia, sino puro determinismo. Sólo hay Historia donde hay tiempo problematizado y no pre-dado. La inexorabilidad del futuro es la negación de la Historia" (Pedagogía da autonomia, 80-81).

${ }^{36}$ Una de las condiciones para que se produzca un aprendizaje significativo es partir de los conocimientos previos del alumnado. En Pedagogía de la esperanza, Freire indica dos premisas clave para el educador: a) nadie debería enseñar lo que sabe sin saber lo que saben y en qué nivel, aquellos a quienes va a enseñar lo que sabe, y b) nadie debería enseñar lo que sabe sin respetar ese saber del alumnado, parte del cual está implícito en la lectura del mundo de los que van a aprender lo que sabe el que va a enseñar (82).

${ }^{37}$ Asimismo, Freire aboga por la responsabilidad del educador al elegir los contenidos del programa: debe enseñar lo que parece fundamental en el tiempo y en el espacio en el que se encuentra.
} 
curiosidad por un saber verdadero, y que conlleva el fomento por parte del educador de las preguntas e incluso de la reflexión crítica sobre las mismas ${ }^{38}$.

Ante este panorama, cobra gran importancia la formación del profesorado, capacitación que apuesta por el modelo de docente reflexivo, que investiga en su práctica. No es el simple técnico que se dedica a implementar recetas de otros, los "expertos". Es un auténtico profesional de la enseñanza. La reflexión crítica sobre la práctica se erige como un momento fundamental en la formación permanente del profesorado, para lo cual, debe primero tomar distancia de su práctica, realizar ese distanciamiento epistemológico que posibilita el auténtico conocimiento, para después desentrañar el saber: cuanto más se asume cómo está siendo y percibe las razones por las que está siendo así, más se vuelve capaz de cambiar, de progresar del estado de curiosidad ingenua al de curiosidad epistemológica (Cartas a quien, 116).

Es la praxis la unión de práctica y teoría, la auténtica formadora para el docente, quien va avanzando en esta espiral dialéctica entre una y otra. Dentro de estas reflexiones, Freire incluye aquellas sobre los condicionamientos que el contexto cultural ejerce sobre él, sobre su modo de actuar, sobre sus valores. Sólo siendo conscientes de ellos, pueden ser superados. En esta formación permanente, el pedagogo brasileño reivindica la constitución de grupos, de colectivos de docentes preocupados por continuar creciendo como profesionales, como educadores. Nada extraño dada la importancia que él concede al diálogo, al intercambio de experiencias, a la comunicación interpersonal. Freire señala que los grupos de formación han de estar liderados por una persona democrática, curiosa, humilde y científicamente competente, con un nivel superior al grupo para que pueda ayudarles en el proceso de develamiento de la realidad. Freire subraya la necesidad de que los grupos tomen conciencia de su identidad: saber para qué, contra qué, a favor de qué, de quién, se comprometen en el mejoramiento de su propio saber. Sólo a partir de aquí podrán descubrir cómo avanzar para tratar de conseguir lo que quieren (Cartas a quien, 125) ${ }^{39}$ :

La práctica docente exige una definición. No puedo ser profesor a favor simplemente del Hombre o de la Humanidad, frase demasiada vaga. Uno ha de concretar: a favor de la decencia contra el impudor, a favor de la libertad contra el autoritarismo, a favor de la autoridad contra la licenciosidad, de la libertad contra la dictadura de derecha o de izquierda, a favor de la lucha constante contra cualquier forma de discriminación, contra una dominación económica de los individuos o de las clases sociales, contra el orden capitalista vigente creador de miseria para cantidades ingentes de población, a favor de una esperanza que me anima a pesar de todo (Pedagogía da autonomía, 115).

Hay además una idea muy importante en el tema de la formación de los educadores que nos interesaría resaltar, mas teniendo en cuenta nuestro interés por lograr una escuela, y una sociedad, por supuesto, auténticamente democrática. Freire incluye en el apartado de la formación, no sólo a los profesores y maestros, sino a todos lo que constituyen la verdadera comunidad educativa, pues toda ella debe estar implicada en la toma de

\footnotetext{
38 "Los niños necesitan crecer en el ejercicio de esta capacidad de pensar, de preguntarse y de preguntar, de dudar, de experimentar hipótesis de acción, de programar y de casi no seguir programas, más que propuestos, impuestos. Los niños necesitan tener asegurado el derecho de aprender a decidir, que sólo se hace decidiendo" (Pedagogía de la indignación, 70).

${ }_{39}$ Recursos que Freire propone en la formación del profesorado son: lectura de periódicos y revistas, estableciendo conexiones entre los hechos comentados, sucesos,... y la vida de la escuela; reuniones interdisciplinarias periódicas, juntando diferentes grupos para el debate de un mismo tema, visto desde ángulos diferentes, aunque relacionados, para evitar el riesgo de un negativo especialismo de los grupos de estudio en cuanto contextos teóricos; permuta de programas entre diferentes grupos de formación, que incluyese videos sobre los trabajos de formación de los propios grupos, etc.
} 
decisiones referida al terreno de la educación. Habla de los vigilantes, de las cocineras, de los cuidadores, en definitiva, de lo que nosotros denominaríamos personal de administración y servicios, junto con los padres y madres del alumnado ${ }^{40}$. No se trata de excluir a los "especialistas" de la toma de decisiones relativas al currículo, sino de abrir al debate social cuestiones tan importantes como la finalidad que perseguimos con el proceso educativo, qué tipo de persona queremos conseguir, con qué medios contamos, etc. Freire señala el deber de los progresistas y demócratas de defender la presencia crítica de las clases populares en los debates sobre el destino de la ciudad, de la escuela, que no es sino proteger su derecho a hacer uso real de su ciudadanía ${ }^{41}$.

\section{A modo de epílogo}

Freire insiste en sus obras: cambiar es difícil pero es posible. A partir de este saber fundamental, hemos de programar nuestra acción político-pedagógica, no importa si el proyecto con el cual nos comprometemos es de alfabetización de adultos o de niños, si es de acción sanitaria, si es de evangelización, si es de formación de mano de obra técnica. Y no basta con querer sino que hay que actuar, por lo cual hemos de pensar en las estrategias que mejor nos ayuden a cumplir nuestros objetivos ${ }^{42}$. Quizás no podamos de la noche a la mañana transformar la sociedad en nuestra utopía, quizás no podamos expulsar de un golpe toda la corrupción y las miserias que invaden nuestro planeta, pero ello nunca puede ser óbice para paralizarnos, para pararnos, para derrotarnos.

\footnotetext{
${ }^{40}$ Freire relata que precisamente de esta formación permanente científica se encargó siendo Secretario de Educación de la ciudad de Sao Paulo, de enero de 1989 a mayo de 1991 (Pedagogía de la esperanza 20). Sin embargo, ello no excluye la presencia de especialistas: "Defender la presencia participativa de alumnos, de padres de alumnos, de madres de alumnos, de cuidadores, de cocineras, de porteros, en los estudios de los cuales resulte la programación de los estudios de las escuelas, lo que la Secretaría Municipal de Educación de Sao Paulo ensaya hoy en la administración petista de Luiza Erundina, no significa negar la actuación indispensable de los especialistas. Significa simplemente no dejarlos como "propietarios" exclusivos de un componente fundamental de la práctica educativa. Significa democratizar el poder de elección de los contenidos a que se extiende, necesariamente, el debate sobre el modo más democrático de tratarlos, de proponerlos a la aprehensión de los educandos, en lugar de su simple transferencia por el educador a los educandos. Y esto es lo que también sigue sucediendo en la Secretaría de Educación de Estado de Sao Paulo. No es posible democratizar la elección de los contenidos sin democratizar su enseñanza" (Pedagogía de la esperanza, 105).

${ }^{41}$ Es posible encontrar fuertes relaciones entre el discurso teórico freireano y las actuaciones que el presidente Lula da Silva está llevando a cabo en Brasil. Entre las primeras actuaciones de Lula como presidente, éste ha creado un Consejo de Desarrollo Económico y Social que pretende ser un órgano que sirva de puente entre la sociedad civil y el Gobierno. Consta de 97 personas y hay representantes de todos los campos: cultura, comercio, justicia, finanzas, agropecuaria, la Iglesia -católica y evangélica-. Como presidente ha sido nombrado el ex alcalde de Porto Alegre, Tarso Genro, del Partido de los Trabajadores, ciudad donde se ha llevado la experiencia piloto del llamado "presupuesto participativo", que permite a los ciudadanos, reunidos en comunidades de barrio, intervenir activamente en el presupuesto del municipio. Este Consejo de Desarrollo Económico y Social, a nivel nacional, tiene como finalidad analizar las propuestas de ley que el Gobierno lleve al Parlamento o proponer ellos mismos ideas. El Gobierno las pasará al Parlamento para que las analice sabiendo que son la expresión de un microcosmos de la sociedad (El País, 2003: 11).

${ }^{42}$ Querer es fundamental pero no es suficiente. También es preciso saber querer, aprender a saber querer, lo que implica aprender a saber luchar políticamente con tácticas adecuadas y coherentes con nuestros sueños estratégicos. Lo que no me parece posible es hacer nada o muy poco delante de las terribles diferencias que nos marcan. $Y$ en materia de construir para hacer el mundo, nuestro mundo, menos malo, no tenemos por qué distinguir entre acciones modestas o retumbantes. (...) En este sentido, es tan válida y necesaria la presencia de un líder sindical en una fábrica, explicando la razón de ser de la huelga en marcha en la madrugada y frente a los portones de la empresa, como indispensable es la práctica docente de una maestra que en una escuela de la periferia habla a sus alumnos sobre el derecho a defender su identidad cultural. El líder operario en el portón de la fábrica y la maestra en el salón de clase, ambos tienen mucho que hacer (Cartas a quien, 78).
} 
Empecemos por lo cercano, por el ámbito local, por el más próximo, y ya estaremos sembrando una semilla que más tarde dará sus frutos. Es necesario abrir caminos dentro de lo posible, sin caer en idealismos abstractos y sin rechazar espacios de lucha, por muy pequeños que nos parezcan. En todo momento sólo podemos hacer lo históricamente viable.

\section{Referencias Bibliográficas}

\section{Obras de Paulo Freire en castellano43}

A la sombra de este árbol. Barcelona: El Roure, 1997 (1995).

Acción cultural para la libertad. Buenos Aires: Tierra Nueva, 1975 (1968).

"Acción cultural y concienciación", en La naturaleza política de la educación, Cultura, poder y liberación. Barcelona: Paidós-MEC, 1990.

Cambio. Bogotá: Editorial América Latina, Bogotá, 1970.

Cartas a Cristina. Reflexiones sobre mi vida y mi trabajo. México: Siglo XXI, 1996 (1994).

Cartas a Guinea-Bissau. Apuntes de una experiencia pedagógica en proceso. Madrid: Siglo XXI, $2^{\mathrm{a}}$ edición, 1978 (1977).

Cartas a quien pretende enseñar. México: Siglo XXI, $7^{\text {a }}$ edición, 2001 (1993).

Concientización: teoría y práctica de la liberación. Buenos Aires: Búsqueda,1974.

Conversando con educadores. Montevideo: Roca Viva, 1990.

Educación y acción cultural. Madrid: Zero, 1979.

Educación y cambio. Buenos Aires: Búsqueda, 1976 (1970) (Título original: Cambio).

"Entrevista con Paulo Freire", en Cuadernos de Educación, Serie Orientaciones, No. 26, 1973, Revista de Chile.

Entrevistas con Paulo Freire. México: Gernika, 1978.

Extensión o comunicación. La concientización en el medio rural. Buenos Aires: Siglo XXI, 1973 (1969).

Hacia una pedagogía de la pregunta. Conversaciones con Antonio Faúndez. Buenos Aires: La Aurora, 1986.

La desmitificación de la concientización y otros escritos. Bogotá, Ed. América Latina, 1975.

La educación. Autocrítica de Paulo Freire/lvan Illich. Buenos Aires: Búsqueda, 1986 (1975).

"La educación y el proceso de cambio social"; en Educación y cambio. Buenos Aires: Búsqueda, 1976.

"La desmitificación de la concientización", conferencia pronunciada en Cuernavaca (México), en 1971, en La desmitificación de la concientización y otros escritos. Bogotá: América Latina, 1975.

La educación como práctica de la libertad. Madrid: Siglo XXI, 7ª edición, 1986 (1967).

La educación en la ciudad. México: Siglo XXI, 1997 (1991).

La importancia de leer y el proceso de liberación. Madrid: Siglo XXI, $2^{\text {a }}$ edición, 1984 (1982).

La naturaleza política de la educación. Cultura, poder y liberación. Barcelona: PaidósMEC, 1990 (1985). 
Las Iglesias, la educación y el proceso de liberación humana en la historia. Buenos Aires: La Aurora, $3^{a}$ edición, 1975 (1974).

Pedagogía del oprimido. Madrid: Siglo XXI, 9a edición, 1984 (1970).

Pedagogía de la autonomía. México, Siglo XXI, 1998 (1996).

Pedagogía de la esperanza. Un reencuentro con la Pedagogía del Oprimido. Madrid: Siglo XXI, 1993 (1992).

Pedagogía de la indignación. Madrid: Morata, 2001.

Pedagogía y acción liberadora. Bilbao: Zero, Colección “Lee y Discute”, No. 94, 2ª edición, 1979 (1974).

Política y educación. México: Siglo XXI, 2ª edición, 1997 (1993).

¿Qué es la concientización y cómo funciona? Lima: Causachum, 1975.

Freire, P., y Betto, F. Esta escuela llamada vida. Buenos Aires, Legasa, 1988 (1985).

Freire, P., Fiori, H. y Fiori, J. L. Educación liberadora. Madrid: Zero, 4a edición, 1978 (1974).

Freire, P., Gadotti, M., Guimaraes, S. y Hernández, I. Pedagogía: diálogo y conflicto. Buenos Aires: Cinco, 1987 (1985).

Freire, P., Illich, I. Diálogo. Buenos Aires: Búsqueda-Celadec, 1975.

Freire, P,; Illich, I. y Furter, P. Educación para el cambio social, Buenos Aires: Tierra Nueva, 1974.

Freire, P., y Macedo, D. Alfabetización. Lectura de la palabra y lectura de la realidad. Barcelona: Paidós-MEC, 1989 (1987).

Freire, P. y otros. La animación sociocultural: una educación para el desarrollo. Recopilación de las ponencias presentadas en el seminario de mismo título realizado en Madrid del 30 de marzo al 2 de abril de 1987. Madrid: Fundación Banco Exterior de España, 1988.

\section{Obras de Paulo Freire en portugués}

Pedagogía da autonomia. Saberes Necesarios á Prática Educativa. Paz e Terra, 13a edición, 1999.

\section{Escritos sobre Freire}

AA. VV. "Apuntes bibliográficos sobre Paulo Freire", en Cuadernos de Pedagogía, No. 7/8. Barcelona, julio-agosto (1975): 31-32.

Mexicano, Vol. VIII, No. 1, 1971.

Abraham, K. "Education for revolution: the significance of Paulo Freire's thought", en Religion and Society, No. 20. Bengala: Christian Institute for the Study of Religion and Society, junio (1973): 29-37.

Araújo Freire, A. M. A voz da esposa. A trajetoira de Paulo Freire. São Paulo: Instituto Paulo Freire (1996) <http://www.paulofreire.org $>$

Aguad, E. y Tagle, C. "La concientización como praxis", en Hoy en el Trabajo Social, No. 25, diciembre, editorial Ecro, Buenos Aires. (1972): 7-23.

Apple, M. Educación y poder. Barcelona: Paidós, 1982. 
Arias, J. "Lula crea un órgano de la sociedad civil para intervenir en política", en El País, 8 de febrero de 2003.

Blanco, R. La pedagogía de Paulo Freire. Ideología y método de la educación liberadora. Madrid: Zero zyx, 1982.

D'arcy, M. "Pedagogy and Politics: Education of Adults in Latin America", en Convergence, Vol. IV, No. 1(1971): 9.

Escobar Aguirre, J. M. Paulo Freire: otra pedagogía política. Madrid: Editorial de la Universidad Complutense, 1990.

Facundo, B. Freire Inspired Programes in the United States and Puerto Rico. A Critical Evaluation. http://www.nlu.nl.edu

Fernández Fernández, J. A. "Paulo Freire y la educación liberadora", en Trilla, J. (coord.) El legado pedagógico de siglo XX para la escuela del siglo XXI. Barcelona: Grao, Barcelona, 2001 pp. 313-342.

Fiori, J. L. "Dialéctica y Libertad", en Freire, P., Fiori, H. y Fiori, J. L. Educación liberadora. Madrid: Ed. Zero zyx, Biblioteca "Promoción del pueblo" No. 17, 4a edición, noviembre (1978) (1 $1^{\mathrm{a}}$ edición, noviembre 1974): 51.

Gadotti, M. A voz do biografo brasileiro. http://www.paulofreire.org

Giroux, H. Introducción a Freire, P. La naturaleza política de la educación, Cultura, poder y liberación. Barcelona: Paidós-MEC, 1990, p.14.

Gómez García, María N. Los conceptos educativos en la obra de Paulo Freire. Madrid: Anaya, 1982.

Grabowski, S. (ed.) Paulo Freire: A Revolutionary Dilemma for the Adult Educator. Syracuse University Publications in Continuing Education, 1973. En este libro se encuentra una bibliografía de referencias sobre Paulo Freire preparada por Anne Hartung y John Ohliger. Dicha bibliografía apareció en castellano en la revista Centro de Estudios Educativos (CEE), Vol. III, No. 1, México: 98-135.

Inodep. El mensaje de Paulo Freire. Teoría y práctica de la liberación. Textos seleccionados por el Inodep, Fondo de Cultura Económica. Madrid: Marsiega, No. 16-17, $5^{\mathrm{a}}$ edición, 1980.

Macedo, Donaldo. "Freire Revisión de la pedagogía crítica. Entrevista a Paulo Freire”; en La naturaleza política de la educación. Cultura, poder y liberación. Barcelona: PaidósMEC, 1990. (Edición original: 1985): 195.

Mijarc, K. "Comment Paulo Freire voulait changer les Brésiliens",; en Terre Entière, No. 34 (1969):8-38.

Monclús, A. Pedagogía de la contradicción. Paulo Freire: nuevos planteamientos en educación de adultos. Barcelona: Anthropos, 1988.

Pantoja Leite, A. L. "Educaçao e Conscientizaçao”, en Sintese. Río de Janeiro: Sociedad Brasileira de Educaçao, Vol. II, No. 5, nova fase, oct-dizembro (1975): 53-85.

Revista de Ciencias de la Educación, No. 10, octubre de 1973.

Revista Diálogos de Barcelona. Dedicó varios artículos a Freire en los Nos 11-12 y 15-16.

Revista Documentación Social. Publicó un número extraordinario, el No. 110, sobre Paulo Freire (Madrid, 1988). Posteriormente, fue publicado como libro: Educación $y$ transformación social. Homenaje a Paulo Freire. Caracas: Laboratorio Educativo, 1988.

Revista Perspectiva de Diálogo, No. 50, diciembre de 1970. Está dedicada a la educación liberadora, con abundantes referencias bibliográficas a Paulo Freire. 
Revista Temps d’Educación de Barcelona. Dedicó varios artículos a Freire en el primer semestre de 1989.

Rosiska Darcy De Oliveira, P. D. "Pedagogía del oprimido. Opresión de la pedagogía. El debate pedagógico", en Cuadernos de Pedagogía, No. 7-8 (1975): 5 y ss.

Ruiz Olabuenaga, J. y otros. Paulo Freire: conscientización y andragogía. Buenos Aires: Paidós, 1975.

Sanders, T. G. "The Paulo Freire Method: Literacy Training and Conscientization", en American Universities Field Staff, Report, West Coast South America, Series. Santiago de Chile, Vol. XV, No. 1 (1968): 18.

Torres, J. Prólogo a Pedagogía de la indignación. Madrid: Morata (2001): 11 y ss.

Torres, R. María. Discurso y práctica en educación popular. Quito: Textos, 1988.

Torres Nova, Carlos (comp.) Entrevistas con Paulo Freire. México: Gernika, 1978.

Trimarchi, M. "Il concetto di "tolleranza" contradice il rispetto dei diritti umani", en Cultura e Natura, No. 3. Roma (1994): 5.

Weffort, F. C. "Educaçao e Política" (Reflexoes sociológicas sobre una pedagogía da liberdade); en Educaçao como práctica da liberdade. Río de Janerio: Paz e Terra (1967): 3-26.

\section{Páginas web recomendadas}

Instituto Paulo Freire: http://www.paulofreire.org

http.//www.fronesis.org

http://www.nlu.nl.edu

http://www.uni.edu

http://www.irn.pdx.edu

http://www.artefact.be

http://www.trubeat.com

http://www.lesley.edu

http://www.freire.de

En España: Centro de Investigación Social y Educativa, CREA, de la Universidad de Barcelona: http://www.ub.es/div-fac/div5/serveis/crea/crea1.htm

Asociación Alforja: http://www.alforja.or.es 